\title{
Personal View-An alternative vacation: My experience with the Tiyanjane and Umodzi palliative care teams at Queen Elizabeth Central Hospital
}

\section{Limula}

Year 5 Student, Bachelor of Medicine, Bachelor of Surgery (MBBS), College of Medicine, University of Malawi, Blantyre, Malawi

E-mail: climula@gmail.com

After receiving a number of lectures on palliative care during the early part of medical school, my impression was that we were learning these principles to apply them in the contexts of end-of-life care and pain management, for example, when we become doctors of whatever specialty in the future. It was not until third year that I was introduced to the concept of palliative care as a professional specialty itself (and a possible future career option). My curiosity led me to researching further about palliative care out of my own interest. I learned that "palliative care provides relief from pain and other distressing symptoms, affirms life and regards dying as a normal process, and intends neither to hasten nor postpone death". ${ }^{1}$ I came to realize that palliative care is not about disease cure but an individual as a holistic being, and helping the patient in all aspects of life: physical, spiritual, social and psychological. ${ }^{2}$ It also helps families cope with the patient's illness and their own bereavement. It is about "adding life to days and not just days to life".

At the end of third year, I decided to seek out some firsthand experience of the specialty by spending some of my holiday time with the Tiyanjane and Umodzi palliative care programmes. These are, respectively, the adult and paediatric palliative care programmes at Queen Elizabeth Central Hospital (QECH). Umodzi was started in 2001 and Tiyanjane in 2003. They provide palliative care services to patients at QECH and-through outreach and training-to the whole Southern Region of Malawi. This includes inpatient care, outpatient clinics, and home-based care in the community. ${ }^{3}$

Each day with the palliative care team is different, but generally the work involves providing care for both existing and new patients from all departments of the hospital and from peripheral centres.

I had a life-changing experience when I was given the privilege of being part of a home visit team. We went to Chemusa, where we visited an 85-year-old lady with cancer of the thyroid gland, which had spread to the bones. She had a huge swelling on her left upper arm, which was very painful. When we arrived at her home, she was sitting outside her house groaning in pain. She was taking morphine, but her pain was not well controlled. We encouraged her and addressed her concerns, one of which was lack of visitation from family and friends. Her niece, who was her dearest relative and friend, had passed away few years earlier, and she missed the kind of bond that they had shared. She felt God had abandoned her because the church members who used to visit her had stopped visiting. In order to control her pain, her morphine dose was increased. I could see the relief in the old lady, and it was so touching. By the time we were leaving, she could not fully express her gratitude; she was comfortable and joking around with us. She announced her blessings on us. I felt satisfaction and joy within me.
One thing I have realized is that patients are often treated for a condition of which they have no knowledge at all. The reason for poor patient knowledge is multifactorial, ranging from the health care providers' lack of communication to patients not asking clinicians for more information. Tiyanjane and Umodzi provide counselling services to the patients. I noted that, by speaking truthfully to patients, they are more likely to adhere to their course of treatment. Communication, itself, is therapeutic and also contributes to patient quality of life.

\section{Example of shared care by the palliative and internal medicine teams at QECH}

During my attachment, I saw a patient in the medical ward who had disseminated Kaposi's sarcoma (KS). She had generalized oedema and was constipated and oliguric. She was screaming in pain at the time we arrived at her bed. She was already on morphine but still in excruciating pain. After she was assessed, the dose of morphine was increased and she was given bisacodyl suppositories and metronidazole powder to apply to her severely infected KS lesions. The internal medicine team supported care by performing a therapeutic pleural tap. When I saw her some time later on the ward, the patient was comfortable, the KS lesions had become more tolerable to her and no longer gave off a foul smell, and her pain was well controlled. I witnessed an enormous improvement of the patient before she was discharged. Upon being discharge from the hospital, she was booked for further management and counselling at Tiyanjane KS clinic.

\section{Moving forward}

Palliative care has been active in Malawi for over ten years, but many people still have little or no understanding of this important area of medical practice. Many countries in Africa still have no palliative care services despite the fact that palliative care employs inexpensive medications and interventions. I believe the time has come for Malawi to embrace palliative care as an important component of our essential health package, and I would like to appeal to health professionals, as well as medical students, to study palliative care and to advocate for its widespread implementation in our country. Let us embrace change and, in doing so, give relief to many.

\section{References}

1. WHO definition of palliative care [Internet]. Geneva: World Health Organization; 2012 [updated 2012 Jan 28; cited 2015 Jun 4]. Available from: www.who.int/cancer/palliative/definition/en/.

2. Palliative Care Support Trust [Internet]. Blantyre: Palliative Care Support Trust; c2011 [cited 2015 Jun 4]. Available from: www.palliativecaresupportmw.org.

3. Bond C, Lavy V, Woolridge R. Palliative care toolkit: improving care from the roots up in resource-limited settings [Internet]. London: Help the Hospices; 2008 [cited 2015 Jun 4]. Available from: http://vd.pcn.net/en/index.php?option $=$ com_docman\&task $=$ doc_ download\&gid $=28 \&$ Itemid $=31$. 